in grammes of weight of the $\mathrm{U}$ tube, $\mathrm{B}$ gives the number of grains of sulphuretted hydrogen in 100 cubic feet, and $\mathrm{C}$ the percentage :

A.

No. $1 \ldots \ldots \ldots . .1085$

No. $2 \ldots \ldots \ldots . .1100$

No. $3 \ldots \ldots \ldots . .1110$

No. $4 \ldots \ldots \ldots . .1100$
B.

344.91

339.52

342.59

341.00
C.

0.51 per cent.

0.52 " " "

$0.52 " 6$

$0.52 \div 4$

These I consider as agreeing very closely.

A few days after I began the experiments upon the finished gas and was surprised to find that the 1 -tube gained more in weight than it did when using the unpurified, sometimes showing as much as 100 grains more in 100 eubic feet, while the Referee's apparatus, as used by Dr. Love and also by myself, did not give over 10 grains of total sulphur.

After a few attempts I found the sulphate of copper assumed a peculiar tint different from what I had seen while working on the unpurified gas, and, thinking that the sulphuric acid liberated might be in some way acting upon sone of the hydrocarbons, I took some of the sulphate out of the tube and treated it with absolute alcohol and also with ether, and obtained a peculiar oily substance, apparently a mixture of hydrocarbons, but have not as yet been able to obtain a sufticient quantity of it to make any experiments upon it, but hope to be able to do so before long. This was sufficient to prove to me what caused the increase in weight of the $U$-tube and showed that it was not due to sulphuretted hydrogen.

I have not yet had an opportunity to try this method on unpurified coal gas, but according to Mr. Wright's statements it gives very satisfactory results.

\title{
ON THE FRACTIONAL DE-HYDRATION OF AMMONIUM ALUM, AND THE ATOMICITY OF ALUMINUM.
}

\section{By J. W. Mallet,}

In the course of experiments preparatory to my investigation of the atomic weight of aluminum, ${ }^{\text {I }}$ examined the behavior of crystallized ammonium-aluminum alum when dried under various conditions, among otbers when placed over sulphuric acid in a desiccator. 
The question of the extent to which water of crystallization is removable, under well-defined conditions, from the alums, bears. upon the adoption of the formula

or

$$
\mathrm{M}^{\prime} \mathrm{M}^{\prime \prime \prime}\left(\mathrm{SO}_{4}\right)_{2} 12 \mathrm{H}_{2} \mathrm{O}
$$

$$
\mathrm{M}^{\prime} \mathrm{M}^{\prime \prime \prime}{ }_{2}\left(\mathrm{SO}_{4}\right)_{4} 24 \mathrm{H}_{2} \mathrm{O}
$$

as correctly representing one of these salts. This question has been discussed by Lupton and Watts, $\dagger$ on the basis of the experiments of Hertwig; $t$ Lupton $\S$ and Heintz,\| with the general result that in sundry cases the amounts of water lost, by heating to definite points of temperature, or by evaporation of a solution mixed with excess of sulphuric acid, point to the second of these formulæ, from which odd numbers-such as 19,21 and 23 - of molecules of water may be withdrawn, and which therefore cannot be halved and thus reduced to the simpler formula if but a single molecule of the anhydrous salt be supposed to be present in the residue.

Having ascertained that ammonium-aluminum alum loses largely of its water of crystallization by exposure to air of ordinary atmospberic temperature and pressure dried by a surface of sulphuric acid, and that the loss, even after it has become very slow, goes on for a very long time, I determined, as a separate question from that with which I was chiefly occupied, to continue the drying under these conditions until loss of weight should cease, and see what number of molecules of water would be left. The experiment lasted more than two years, weighings being made at first at intervals of a few hours, then of a day, of two days, of two weeks, and, toward the end, of a month. The temperature of the room, which in winter was warmed continuously by night as well as day, ranged generally about from $20^{\circ}$ to $27^{\circ} \mathrm{C}$., but occasionally passed these limits to a considerable extent during long-continued periods of hotter or colder weather out of doors, and such variations of temperature as occurred made themselves perceptible in the more or less rapid loss of weight of the salt experimented on. The alum was in the form of a fine crystalline meal, spread out to the depth of 7 or 8 millimeters over the surface of a platinum capsule about

† Watts' Dictionary of Chemistry, 3d Suppl., Part I., pp. 65, 66.

$\ddagger$ Pogg. Ann., 18., 99.

$\S$ Chem. Soc. Jour. (Lond.) [?], xiii., 201.

\| Pogg. Ann., iv., 331. 
$10 \mathrm{~cm}$. in diameter. 'The desiccator was of large size, and furnished with a drying tube, containing sulphuric acid, communicating with the outside air, so that the pressure within scarcely differed at any time from that of the atmosphere without.

The following were the results obtainer.

Weight of alum at commeneement of experiment $=39.1654$ grams.

$$
\begin{aligned}
& \text { Loss after } 0 \text { day } 9 \frac{1}{3} \text { hours- .1839 gram. } \\
& \text { " } \\
& \text {. }
\end{aligned}
$$

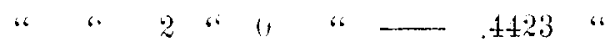

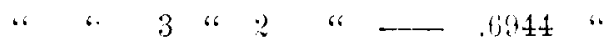

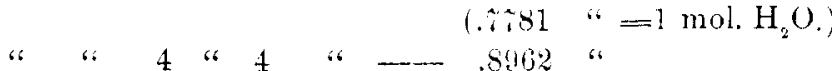

$$
\begin{aligned}
& \because 65 \text { " } 68 \frac{1}{2} " 1.1 .03 \text { " } \\
& \left(1.5562 "=2 \mathrm{H}_{22} \mathrm{O}\right. \text {.) }
\end{aligned}
$$

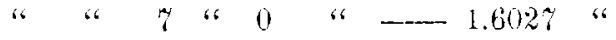

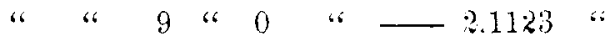

$$
\begin{aligned}
& \text { " }
\end{aligned}
$$

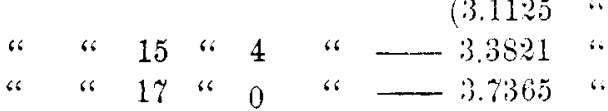

$$
\begin{aligned}
& \left(3.8906 "=5 \mathrm{H}_{2} \mathrm{O}\right. \text {.) }
\end{aligned}
$$

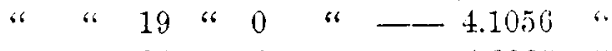

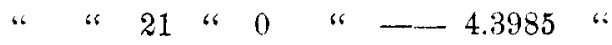

$$
\begin{aligned}
& \text { ( } \left.+.668 \% "=6 \mathrm{H}_{2} \mathrm{O} .\right)
\end{aligned}
$$

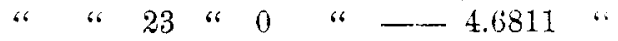

$$
\begin{aligned}
& \text { " " } " 25 \text { " } 300 \text { " }
\end{aligned}
$$

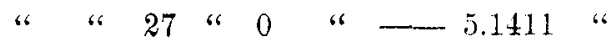

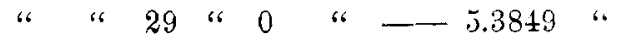

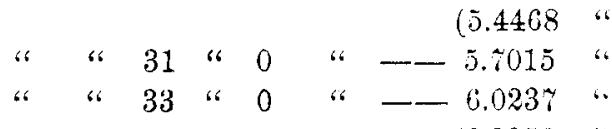

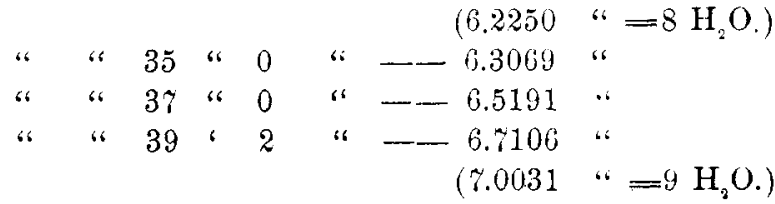


Loss after 4:2 day 2 hours- -7.0279 gram.

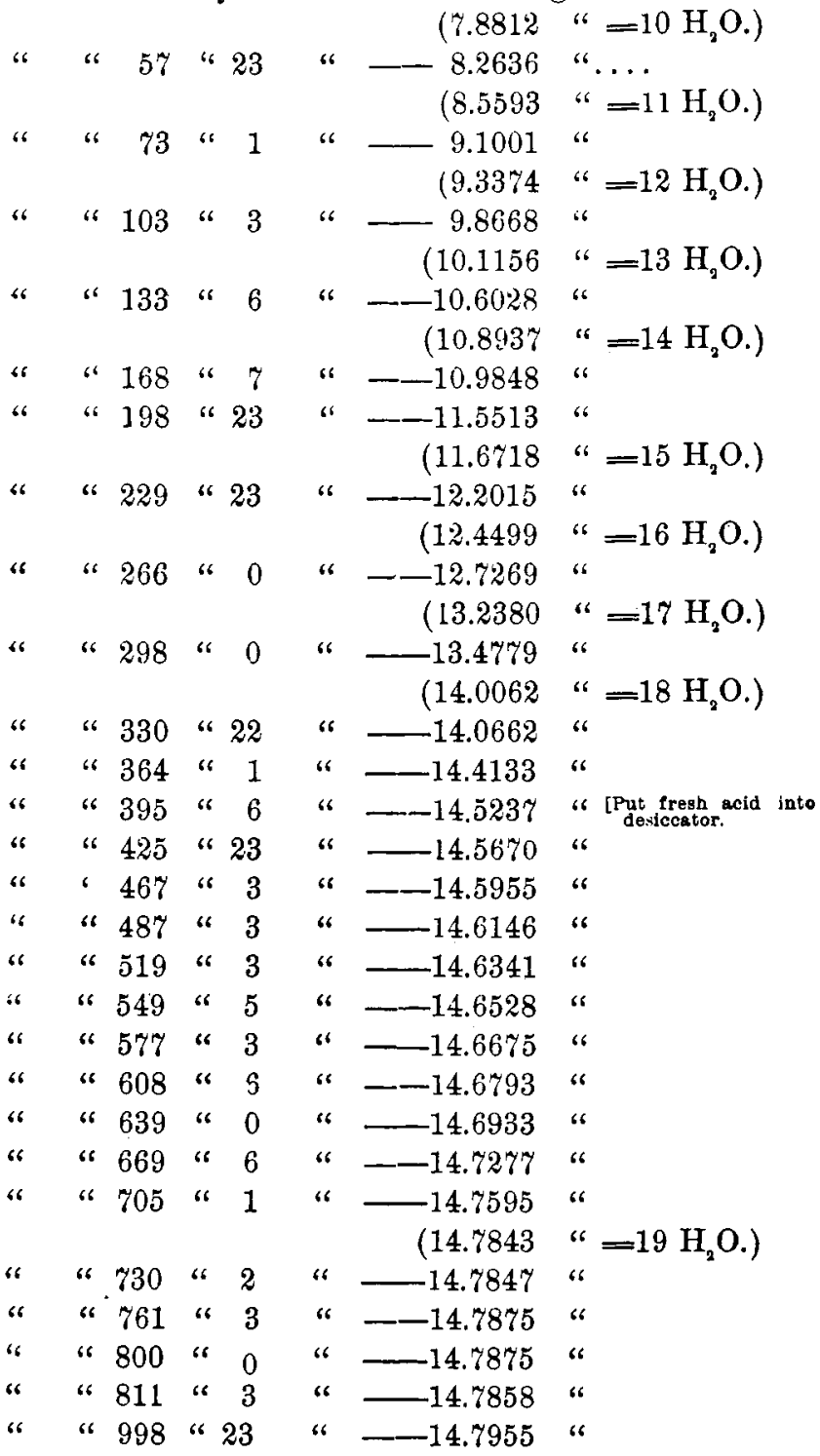

Hence it appears that by exposure to dried air under the conditions stated, ammonium alum loses 19 out of 24 molecules of 
water, and thus adds one case of definite partial de-bydration to those cited by Lupton and Watts * in favor of the layer formula - - the observed residues standing as follows (Watts"table, copied from Lupton's paper, with the case now reported added in brackets):

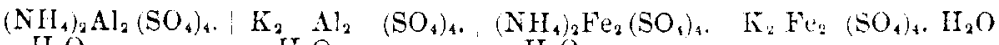

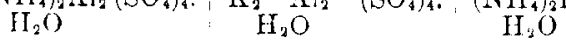

$$
\mathrm{K}_{2} \underset{3 \mathrm{H}_{2} \mathrm{O}}{\mathrm{A} !_{2}}\left(\mathrm{SO}_{4}\right)_{4} \ldots \quad \mathrm{K}_{2} \mathrm{Al} \mathrm{I}_{2}\left(\mathrm{SO}_{4}\right)_{4} .3 \mathrm{H}_{2} \mathrm{O}
$$

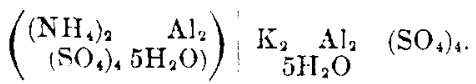

If the rate of loss in the interval between the weighings next above and below that corresponding to each molecule be assumed as uniform, it appear's that the

\begin{tabular}{|c|c|c|c|c|}
\hline $2 d$ & " & $"$ & $\because$ & $78 \frac{1}{2}$ \\
\hline $3 \mathrm{~d}$ & "6 & ". & ". & $78 \frac{1}{2}$ \\
\hline 4 th & " & $\because$ & ". & $90^{\circ}$ \\
\hline $5 \mathrm{th}$ & $\because$ & $"$ & $\because$ & 96 \\
\hline bth & "، & $"$ & 6 & 122 \\
\hline "th & . & $"$ & $\therefore$ & 155 \\
\hline Sth & ." & " & '. & 120 \\
\hline gth & ، & ، & $\because$ & $18:$ \\
\hline 10 th &. & " & ." & 231 \\
\hline 11 th & c &. & ". & 282 \\
\hline $1: \mathrm{th}_{1}$ & " & $\cdots$ & . & 453 \\
\hline $13 \mathrm{th}$ & “، & $"$ & .. & .44 \\
\hline 14th & $"$. & " & $،$ & 1121 \\
\hline 15 th & " & "، & " & 1065 \\
\hline $16 \mathrm{th}$ & " & "، & ". & 1024 \\
\hline 17 th & $"$ & " & .. & 969 \\
\hline 18 th $_{\mathrm{h}}$ & " &.$*$ & $\because$ & 964 \\
\hline $19 \mathrm{th}$ & " & ". & ." & 9646 \\
\hline
\end{tabular}

Taking into account the changes of atmospheric temperature, especially the more persistent changes due to season, during the time occupied by the experiment, which began on the $3 d$ of August, there seems to have been a gradual decrease in the rate of loss throughout, unmarked by any abrupt variations, except as regards the last molecule of water given off, the removal of which took 
more than a year, and more than as long as all of the 18 preceding mokecules.

While this experiment sustains the conclusion of Watts that the proper formula for the alums is:

$$
\mathrm{M}_{2}^{2} \mathrm{M}^{122}{ }_{2}\left(\mathrm{SO}_{4}\right)_{4} \cdot 24 \mathrm{H}_{2} \mathrm{O}
$$

I do not perceive that the further conclusion at which he arrives is valid-viz. "This being admitted, it follows that aluminum, chromiutm and iron must be tetratomic." There is no direct evidence of aluminum exhibiting tetrad character.

All its general relations are those of a triad element. In the alums it is not necessary to assume any "linking function" on the part of the two atoms of aluminum. The constitution of ammonium-aluminum alum, for instance, may be:

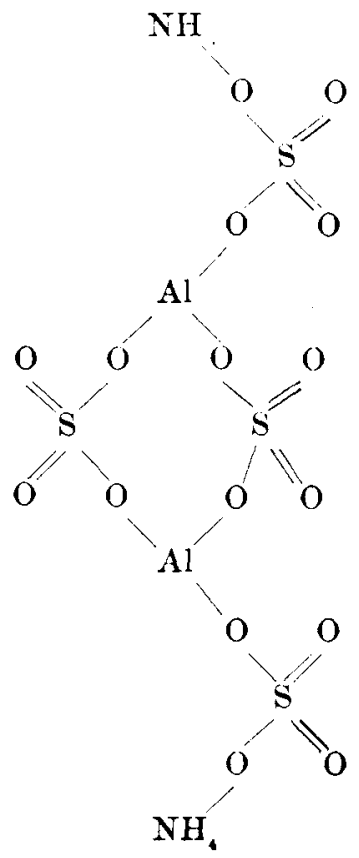

If, however, it be assumed that the two aluminum atoms are directly combined, either in this salt or in the haloid compounds of the metal it seems more probable that in such cases there is double linking, and that aluminum is to be considered as triad or sometimes pentad. Thus the chloride, taking the for- 
mula $\mathrm{Al}_{2} \mathrm{Cl}_{6}$ as established by Deville and Troost's determination of the vapor density, may be represented as:

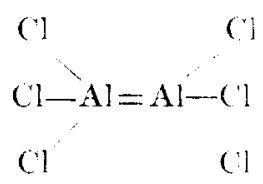

This view seems to reconcile the otherwise conflicting evidence as to atomicity derived from the observed vapor densities of aluminum chloride on the one hand and aluminum methid and ethid on the other. The determinations of Buckton and Odling for the rapor densities of the latter of these compounds are quite inconsistent with the common assumption that aluminum is tetrad.

Uxiv. of Virgixia, Sept. 20, 1882.

\section{ON NITROSACCHAROSE: A CORRECTION.}

By Arthlor H. Hiliotot, l'h. B., F. (. S

In Vol. IV, p. 147 of this Jourual, will be found a paper by me on nitrosaccharose, and at the end of said paper some theoretical conclusions are given which I desire to withdraw.

When the paper was written I was about starting on my summer vacation, and $I$ did not see it again until after it was printed, and a second reading of it showed me I had made a mistake in my figures.

Prof. C.F. Chandler also kindly called my attention to the improbability of the formula given by me to nitrosaccharose. I3ut in assigning the formula given, I was led into error by a corresponding formula found in the Enghsh edition of Wislicenus Strecker's handbook, where the octacetate of saccharose is given as $\mathrm{C}_{12} \mathrm{H}_{14}\left(\mathrm{C}_{2} \mathrm{H}_{3} \mathrm{O}_{2}\right)_{8} \mathrm{O}_{11}$ the correct formula being $\mathrm{C}_{12} \mathrm{II}_{14}\left(\mathrm{O}, \mathrm{C}_{2} \mathrm{H}_{3} \mathrm{O}\right)_{8} \mathrm{O}_{3}$ eight molecules of the group $\mathrm{C}_{2} \mathrm{H}_{3} \mathrm{O}$ replacing the bydrogen in eight molecules of hydroxyl ; thus giving saccharose the formula $\mathrm{C}_{6} \mathrm{H}_{7}(\mathrm{OH})_{4} \mathrm{O}-\mathrm{O}-\mathrm{O}(\mathrm{OH})_{4} \mathrm{C}_{6} \mathrm{H}_{7}$

In regard to the error in my figures, I took the percentage of of cane sugur found and added it to the percentage of $\mathrm{NO}_{3}$. Correctly, I should have taken the percentage of cane sugar minus the hydroxyl, and added this residue $\left(\mathrm{C}_{12} \mathrm{H}_{14} \mathrm{O}_{8}\right)$ to the $\mathrm{NO}_{3}$ found. $\mathrm{By}$ 